\title{
Homologous recombination deficiency in breast cancer
}

\author{
Thomas Bartl · Alex Farr (D)
}

Received: 2 April 2020 / Accepted: 14 May 2020 / Published online: 9 June 2020

(C) The Author(s) 2020

Summary BRCA mutation-related DNA repair deficiencies increase the individual sensitivity to DNAtargeting agents. Therefore, the patient's BRCA mutational status is evaluated in clinical practice as a predictive marker in response to platinum salts and polyADP-ribose polymerase (PARP) inhibitors for breast cancer treatment. A substantial subset of $B R C A$ wildtype breast cancer lesions, however, share both prominent molecular characteristics and clinical behavior patterns with cancer that harbors BRCA mutations, including DNA repair deficiencies. Also referred to as "BRCAness", this observation is related to aberrations of the homologous recombination (HR) repair pathway, which deprive cancer cells of the ability to adequately mend potentially lethal double-strand breaks and result in a BRCA-like genomic instability. Hence, HR deficiency is a promising target for related therapeutic options and the predictive potential of HR testing for treatment response has been increasingly studied. Several HR deficiency-testing assays have been proposed and prospectively validated for various cancer types; however, preliminary results in early breast cancer are inconsistent. As scientific evidence for a potential therapeutic benefit in breast cancer is scarce, HR testing remains highly experimental and should be limited to the boundaries of clinical studies until results of ongoing phase 3 trials are available.

Dr. T. Bartl, MD BA · A. Farr, MD PhD ( $ه)$

Division of General Gynecology and Gynecologic

Oncology, Department of Obstetrics and Gynecology,

Medical University of Vienna, Waehringer

Guertel 18-20, 1090 Vienna, Austria

alex.farr@meduniwien.ac.at

Dr. T. Bartl, MD BA

thomas.bartl@meduniwien.ac.at
Keywords BRCA · Breast cancer · Homologous recombination deficiency $\cdot$ PARP inhibitor

$\begin{array}{ll}\text { Abbreviations } \\ \text { DSB } & \text { Double-strand break } \\ \text { HR } & \text { Homologous recombination } \\ \text { ORR } & \text { Overall response rate } \\ \text { PARP } & \text { Poly-ADP-ribose polymerase } \\ \text { pCR } & \text { Pathological complete response } \\ \text { SSB } & \text { Single-strand break } \\ \text { TNBC } & \text { Triple-negative breast cancer }\end{array}$

\section{Introduction}

Growing evidence supports the increased clinical efficacy of DNA-targeting therapies in breast cancers harboring BRCA1 and/or BRCA2 mutations as BRCA function is pivotal to DNA-damage response [1]. BRCA mutations are observed in approximately $5-10 \%$ of unselected breast cancers and $20-40 \%$ of all triplenegative breast cancers (TNBCs). Up to $15 \%$ more have been hypothesized to express non-BRCA-related alterations in the DNA repair pathway of homologous recombination (HR) repair [2-4]. TNBCs typically express few therapeutic targets; defining a predictive marker to identify patients that will most likely benefit from DNA targeting agents, such as platinum salts and poly-ADP-ribose polymerase (PARP) inhibitors, may therefore expand the therapeutic armamentarium for a clinically highly relevant subset of patients with breast cancer.

\section{Homologous recombination deficiency as a marker for treatment response}

The ability to adequately repair DNA double-strand breaks (DSBs) relies on HR repair, which reconstructs damaged DNA by copying the respective undam- 
aged strand from the homologous sister chromatid. A complex set of proteins is required to interact within this procedure, including the gene products of BRCA1, BRCA2, PALB2, RAD51, ATM, and CHEK2. Any dysfunctional protein involved may impair the ability to adequately mend DSBs, thereby inducing a phenotypical cell behavior termed HR deficiency or "BRCAness." As HR repair fails, DSBs are frequently referred to non-homologous end joining (NHEJ) repair, an error-prone process of random end-to-end fusion of damaged strands, which inevitably leads to information loss, accumulation of genetic damage, and ultimately to cell death. Since the ability of HRdeficient cells to cope with DNA damage is therefore limited, phenotypical HR deficiency is associated with increased sensitivity to therapeutic agents targeting DNA integrity, particularly PARP inhibitors and platinum salts [1].

PARP inhibitors induce an excess of DNA singlestrand breaks (SSBs) by inhibiting the activity of base excision repair and foster DSB by trapping PARP at the DNA, thereby blocking the replication fork [5]. A growing body of evidence, however, also indicates direct involvement of other DNA repair systems, as PARP can be trapped on DNA at sites of unrepaired SSBs, thereby directly contributing to lethal effects of PARP inhibitors [6]. Moreover, radiosensitization effects of PARP inhibition may be explained by interfering with HR-independent so-called PARP1-dependent end-joining [7]. In contrast, the principal effect of platinum salts relies on the induction of interstrand and intrastrand DNA cross-links. The repair of such cross-links depends on a complex interaction of manifold single- and double-strand repair systems including HR. Therefore, deficient cells often fail to restore proper DNA architecture. Moreover, cross-link-related distortions of the DNA double helix promote SSBs and DSBs $[8,9]$.

\section{Defining and diagnosing homologous recombination deficiency}

Several methodologically different approaches to test HR deficiency in breast cancer have been proposed. The so-called "genomic scarring" assays aim to quantify genomic aberrations by next-generation whole genome sequencing. The "myChoice" HR deficiency test (Myriad Genetics Inc., Salt Lake City, Utah, USA) calculates a score of sections of losses of heterozygosity, large-scale transitions, and telomeric allelic imbalance as three combined DNA-based measures of genomic instability [10]. The "CDx BRCA LOH" (Foundation Medicine, Cambridge, Massachusetts, USA) assesses deleterious BRCA1 and/or BRCA2 mutations. With the implementation of HR deficiency testing in treatment decision-making for epithelial ovarian cancer, recent comparative trials have focused on validating genomic scarring assays. Further, recent clinical studies have used genomic scarring assays to assess HR deficiencies in breast cancer [11-14].

Moreover, previously defined complex patterns of somatic mutations throughout the whole genome, socalled gene signatures, have been validated as predictors of HR-deficient tumors. The HRDetect test has been designed to detect HR deficiency with high sensitivity based on such gene signature analyses [15]. It has been hypothesized that such gene signaturebased tests compensate a major shortcoming of genomic scarring assays, i.e., recognition of BRCA promoter hypermethylation-related HR deficiency. Such transcriptional deactivation of $B R C A$ function is reversible and not predictive of therapy response, even though it is associated with higher "myChoice" HR scores. Large studies assessing different HR deficiency tests are urgently needed to clarify these findings [16, 17].

Lastly, protein function of crucial steps in HR such as RAD51 can be assessed using DNA sequencing and immunostaining assays to predict HR deficiency.

Table 1 Clinical trials assessing homologous recombination deficiency in breast cancer patients

\begin{tabular}{|c|c|c|c|c|c|}
\hline Study & Study design & Agent & No & Patients & $\begin{array}{l}\mathrm{pCR} / \mathrm{ORR} \text { in } \mathrm{HRd}^{\mathrm{a}} \text { patients } \\
\text { with or without platinum }\end{array}$ \\
\hline $\begin{array}{l}\text { PrECOG0105/ } \\
\text { pooled Cisplatin-1 and } \\
2 \text { [8] }\end{array}$ & $\begin{array}{l}\text { Phase } 2 \\
\text { single-arm }\end{array}$ & $\begin{array}{l}\text { Carboplatin, gemcitabine, } \\
\text { iniparib and cisplatin + } \\
\text { bevacizumab }\end{array}$ & 148 & $\begin{array}{l}\text { Neoadjuvant } \\
\text { TNBC }\end{array}$ & $\begin{array}{l}\text { pCR: } 42 \% \text { vs. } 10 \% \\
\text { OR } 6.52 ;[1.36-31.2] ; p<0.01 \\
\text { pCR: } 27.5 \% \text { vs. } 0 \% \\
\text { OR } 17 ;[1.91-2249] ; p<0.01\end{array}$ \\
\hline $\begin{array}{l}\text { GeparSixto } \\
{[17]}\end{array}$ & $\begin{array}{l}\text { Phase } 2 \\
\text { randomized } \\
\text { open label }\end{array}$ & $\begin{array}{l}\text { Paclitaxel, doxoru- } \\
\text { bicin } \pm \text { carboplatin }\end{array}$ & 595 & $\begin{array}{l}\text { Neoadjuvant TNBC } \\
\text { and Her2 positive }\end{array}$ & $\begin{array}{l}\text { pCR: } 63.5 \% \text { vs. } 33.9 \% \\
\text { OR } 3.4[1.7-6.9] ; p<0.01\end{array}$ \\
\hline $\begin{array}{l}\text { Gepar0LA (Abstract, } \\
\text { NCT02789332) }\end{array}$ & $\begin{array}{l}\text { Phase } 2 \\
\text { randomized } \\
\text { open label }\end{array}$ & $\begin{array}{l}\text { Olaparib, paclitaxel } \\
\text { versus carboplatin, } \\
\text { paclitaxel }\end{array}$ & 102 & $\begin{array}{l}\text { Neoadjuvant } \\
\text { TNBC or Her2 nega- } \\
\text { tive }\end{array}$ & $\begin{array}{l}\text { pCR: } 20 \% \text { vs. } 56.2 \% \\
\text { OR not reported; } p<0.01\end{array}$ \\
\hline TNT [14] & $\begin{array}{l}\text { Phase } 3 \\
\text { randomized } \\
\text { open label }\end{array}$ & Carboplatin versus docetaxel & 376 & $\begin{array}{l}\text { Unselected ad- } \\
\text { vanced } \\
\text { TNBC }\end{array}$ & $\begin{array}{l}\text { ORR } 38.2 \% \text { vs. } 40.4 \% \\
\text { OR not reported; } p=1.0\end{array}$ \\
\hline
\end{tabular}

$H R$ homologous recombination repair, $O R$ odds ratio, $O R R$ overall response rate, $p C R$ pathological complete response, $T N B C$ triple negative breast cancer aHR deficiency (HRd) was defined by the "myChoice" HR (Myriad Genetics) assay for all studies listed 
Broad availability and independence of commercial testing may favor this approach, especially in lowerincome countries. However, its clinical applicability is limited as $R A D 51$ assays cannot be performed on formalin-fixed paraffin-embedded blocks, but they require viable tumor tissue [17].

\section{Studies assessing homologous recombination deficiency in breast cancer patients}

Despite promising preliminary results, published trials comprise heterogeneous populations and study designs, which hinder direct comparisons and limit drawing conclusions for clinical practice. Table 1 provides an overview of recent clinical studies evaluating the predictive value of HR assessment.

Results appear most promising for predicting therapy response to platinum salts in a neoadjuvant setting. Telli et al. [10] retrospectively assessed the predictive value of the "myChoice" HR test in three singlearm trials (PrECOG0105 and pooled cisplatin 1 and cisplatin 2) of neoadjuvant platinum therapy comprising 148 patients with TNBC. Patients with HRdeficient tumors achieved higher pathological complete response (pCR) rates with the addition of platin (PrECOG0105, pCR 42\% versus 10\%, OR 6.52; 95\% CI $1.36-31.2$, and cisplatin 1 and 2 , pCR $27.5 \%$ versus $0 \%$, OR 17; 95\% CI 1.91-2249).

Moreover, a post-hoc analysis of the GeparSixto trial, a randomized phase 2 study assessing the additional benefit of carboplatin to anthracycline/taxanebased treatment for neoadjuvant chemotherapy regimens in 595 patients with primary, nonmetastatic TNBC and her2-positive breast cancer, reported higher pCR rates in patients with HR-deficient tumors with the addition of carboplatin $(63.5 \%$ vs. $33.9 \%$, OR 3.4, 95\% CI 1.7-6.9) [18]. The long-term survival analysis, however, could not prove a correlation between HR deficiency and patient prognosis [19].

The ongoing randomized phase 2 trial TBCRC030 (NCT01982448) of neoadjuvant cisplatin versus paclitaxel in 140 patients with TNBC preliminarily reported that the pCR rate of patients with HR-deficient tumors was $21.1 \%$ in the carboplatin cohort and $19.4 \%$ in the paclitaxel cohort [20]. The also ongoing GeparOLA (NCT02789332) study, a randomized openlabel phase 2 trial of paclitaxel/olaparib $100 \mathrm{mg}$ BID versus paclitaxel/carboplatin both followed by epirubicin/cyclophosphamide as neoadjuvant treatment in 102 patients with her2-negative early breast cancer, preliminarily reported that pCR rate was not statistically significant different between the olaparib arm and the carboplatin arm. In the subgroup of patients with HR-deficient tumors, pCR rates were $52.6 \%$ in the olaparib arm and $20.0 \%$ in the carboplatin arm, whereas in the subgroup of patients with HR-proficient tumors, the rates were 56.0 and $59.3 \%$, respectively [21].
The TNT trial, a randomized, open-label phase 3 study comparing carboplatin with docetaxel in 376 patients with unselected advanced TNBC, reported that patients with BRCA-mutated tumors achieved higher overall response rates (ORRs) after carboplatin treatment than after docetaxel treatment $(68.0 \%$ versus $33.3 \%)$. There was no significant difference in ORR in patients with HR-deficient tumors after carboplatin and docetaxel treatment (38.2\% versus $40.4 \%)$. This finding could partially be explained by the fact that the HR deficiency test was performed on archival samples of the primary tumor, which could result in lower positive predictive value as tumor evolution processes and inherent accumulation of genomic scars could not be depicted [22].

\section{Future perspectives}

As current evidence is limited, several ongoing clinical trials assessing treatment response to platinum salts and PARP inhibitors, stratified by HR assessment, are expected to further elucidate the role of HR for therapy decision-making in patients with breast cancer. A Chinese randomized phase 3 trial (NCT03876886) is studying dose-dense epirubicin/cyclophosphamide followed by paclitaxel and carboplatin/paclitaxel as adjuvant therapy of TNBC stratified by HR assessment. Moreover, a post-hoc HR deficiency analysis of the BrighTNess phase 3 trial, comparing veliparib plus carboplatin versus carboplatin alone, is currently underway and may provide insights into the predictive value of HR testing in this cohort [23].

The phase III trials OlympiAD and EMBRACA have proved that PARP inhibitors have the potential to increase PFS compared to standard chemotherapy in pretreated advanced BRCA mutated breast cancer $[24,25]$. HR testing could greatly expand the scope of patients benefiting from these treatment options. To prove this hypothesis, several clinical phase 2 trials are currently ongoing, testing the efficacy of PARP inhibitors depending on the HR status; the agents involved in these studies include talazoparib in the TBB (talazoparib beyond BRCA) trial, olaparib in the NOBROLA trial, and rucaparib in the RUBY trial [26, 27]. In addition, a phase 2 three-armed trial (NCT03330847) is testing olaparib in combination with the DNA damage response inhibitors adavosertib and AZD6737, stratified by HR assessment.

\section{Conclusions}

The predictive value of the $B R C A$ mutational status has been validated for platinum salt and PARP inhibitor therapy; however, published trials do not provide evidence of whether HR deficiency is an adequate marker for therapy decision-making in patients with breast cancer. Further studies and large comparative phase 3 trials are warranted to substantiate promising results of the currently published retro- 
spective and early clinical studies. Similar to clinical routines of epithelial ovarian cancer, HR deficiency testing may identify subsets of breast cancer patients that are likely to benefit from platinum salt or PARP inhibition therapy in the future.

\section{Take-home messages}

- Homologous recombination (HR) deficiency may represent a valuable biomarker for therapy response to PARP inhibitors and platinum salts.

- The clinical use of HR deficiency could be of particular importance in women with TNBC.

- Ongoing trials are assessing the predictive value of commercially available "genomic scarring" assays that aim to quantify HR-related DNA-based measures of genomic instability.

- As there is no concrete evidence for the predictive value of HR deficiency, HR testing should currently be limited to clinical trials.

Funding Open access funding provided by Medical University of Vienna.

Conflict of interest T. Bartl and A. Farr declare that they have no competing interests.

Open Access This article is licensed under a Creative Commons Attribution 4.0 International License, which permits use, sharing, adaptation, distribution and reproduction in any medium or format, as long as you give appropriate credit to the original author(s) and the source, provide a link to the Creative Commons licence, and indicate if changes were made. The images or other third party material in this article are included in the article's Creative Commons licence, unless indicated otherwise in a credit line to the material. If material is not included in the article's Creative Commons licence and your intended use is not permitted by statutory regulation or exceeds the permitted use, you will need to obtain permission directly from the copyright holder. To view a copy of this licence, visit http://creativecommons.org/licenses/by/4.0/.

\section{References}

1. Garutti M, Pelizzari G, Bartoletti M, Malfatti MC, Gerratana $\mathrm{L}$, Tell $\mathrm{G}$, et al. Platinum salts in patients with breast cancer: a focus on predictive factors. Int J Mol Sci. 2019;20(14):3390.

2. Tian T, Shan L, Yang W, Zhou X, Shui R. Evaluation of the BRCAness phenotype and its correlations with clinicopathological features in triple-negative breast cancers. Hum Pathol. 2019;84:231-8.

3. Akashi-Tanaka S, Watanabe C, Takamaru T, Kuwayama T, Ikeda $\mathrm{M}$, Ohyama $\mathrm{H}$, et al. BRCAness predicts resistance to taxane-containing regimens in triple negative breast cancer during neoadjuvant chemotherapy. Clin Breast Cancer. 2015;15(1):80-5.

4. Peshkin BN, Alabek ML, Isaacs C. BRCA1/2 mutations and triple negative breast cancers. Breast Dis. 2010;32(1-2):25-33.

5. Yates MS, Timms K, Daniels MS, Oakley HD, Munsell MF, LanchburyJS, etal. Evaluation ofBRCA1/2 and homologous recombination defects in ovarian cancer and impact on clinical outcomes. JClin Oncol. 2017;35(15_suppl):5511.
6. Gogola E, Rottenberg S, Jonkers J. Resistance to PARP inhibitors: lessons from preclinical models of BRCA-associated cancer. Annu Rev Cancer Biol. 2019;3(1):235-54.

7. Kotter A, Cornils K, Borgmann K, Dahm-Daphi J, Petersen C, Dikomey E, et al. Inhibition of PARP1-dependent end-joining contributes to olaparib-mediated radiosensitization in tumor cells. Mol Oncol. 2014;8(8):1616-25.

8. Hinz JM. Role of homologous recombination in DNA interstrand crosslink repair. Environ Mol Mutagen. 2010;51(6):582-603.

9. Legerski RJ. Repair of DNA interstrand cross-links during $S$ phase of the mammalian cell cycle. Environ Mol Mutagen. 2010;51(6):540-51.

10. TelliML, Timms KM, ReidJ,HennessyB, Mills GB, Jensen KC, et al. Homologous Recombination Deficiency (HRD) score predicts response to platinum-containing neoadjuvant chemotherapy in patients with triple-negative breast cancer. Clin Cancer Res. 2016;22(15):3764-73.

11. Gonzalez-Martin A, Pothuri B, Vergote I, DePont Christensen R, Graybill W, Mirza MR, et al. Niraparib in patients with newly diagnosed advanced ovarian cancer. N Engl J Med. 2019;381(25):2391-402.

12. Coleman RL, Fleming GF, Brady MF, Swisher EM, Steffensen KD, Friedlander M, et al. Veliparib with first-line chemotherapy and as maintenance therapy in ovarian cancer. NEngl J Med. 2019;381(25):2403-15.

13. Mirza MR, Monk BJ, Herrstedt J, Oza AM, Mahner S, Redondo A, et al. Niraparib maintenance therapy in platinum-sensitive, recurrent ovarian cancer. N Engl J Med. 2016;375(22):2154-64.

14. Isakoff SJ, Mayer EL, He L, Traina TA, Carey LA, Krag KJ, et al. TBCRC009: a multicenter phase II clinical trial of platinum monotherapy with biomarker assessment in metastatic triple-negative breast cancer. J Clin Oncol. 2015;33(17):1902-9.

15. Davies H, Glodzik D, Morganella S, Yates LR, Staaf J, Zou X, et al. HRDetect is a predictor of BRCA1 and BRCA2 deficiency based on mutational signatures. Nat Med. 2017;23(4):517-25.

16. Sharma P, Barlow WE, Godwin AK, Pathak H, Isakova K, Williams D, et al. Impact of homologous recombination deficiency biomarkers on outcomes in patients with triple-negative breast cancer treated with adjuvant doxorubicin and cyclophosphamide (SWOG S9313). Ann Oncol. 2018;29(3):654-60.

17. Pellegrino B, Mateo J, Serra V, Balmaña J. Controversies in oncology: Are genomic tests quantifying homologous recombination repair deficiency (HRD) usefulfor treatment decision making? ESMO Open. 2019;4(2):e480.

18. Von Minckwitz G, Timms K, Untch M, Elkin EP, Fasching PA, Schneeweiss A, et al. Prediction of pathological complete response ( $\mathrm{pCR}$ ) by homologous recombination deficiency (HRD) after carboplatin-containing neoadjuvant chemotherapy in patients with TNBC: results from GeparSixto. JClin Oncol. 2015;33(15_suppl):1004.

19. Loibl S, Weber KE, Timms KM, Elkin EP, Hahnen E, Fasching PA, et al. Survival analysis of carboplatin added to an anthracycline/taxane-based neoadjuvant chemotherapy and HRD score as predictor of response-final results from GeparSixto. Ann Oncol. 2018;29(12):2341-7.

20. Mayer EL, Abramson VG, Jankowitz RC, Falkson CI, Marcom PK, Traina TA, et al. TBCRC 030: A randomized phase II study of preoperative cisplatin versus paclitaxel in TNBC-Evaluating the homologous recombination deficiency (HRD) biomarker. J Clin Oncol. 2019;37(15_suppl):507. 
21. Fasching PA, Jackisch C, Rhiem K, Schneeweiss A, Klare P, Hanusch C, et al. GeparOLA: A randomized phase II trial to assess the efficacy of paclitaxel and olaparib in comparison to paclitaxel/carboplatin followed by epirubicin/ cyclophosphamide as neoadjuvant chemotherapy in patients (pts) with HER2-negative earlybreast cancer (BC) and homologous recombination deficiency (HRD). JClin Oncol. 2019;37(15_suppl):506.

22. Tutt A, Tovey H, Cheang MCU, Kernaghan S, Kilburn L, Gazinska P, et al. Carboplatin in BRCA1/2-mutated and triple-negative breast cancer BRCAness subgroups: the TNT Trial. Nat Med. 2018;24(5):628-37.

23. Loibl S, O'Shaughnessy J, Untch M, Sikov WM, Rugo HS, McKee MD, et al. Addition of the PARP inhibitor veliparib plus carboplatin or carboplatin alone to standard neoadjuvant chemotherapy in triple-negative breast cancer (BrighTNess): a randomised, phase 3 trial. Lancet Oncol. 2018;19(4):497-509.

24. Robson M, Im SA, Senkus E, Xu B, Domchek SM, Masuda N, et al. Olaparib for metastatic breast cancer in patients with a germline BRCA mutation. N Engl J Med. 2017;377(6):523-33.

25. Litton JK, Rugo HS, Ettl J, Hurvitz SA, Goncalves A, Lee KH, et al. Talazoparib in patients with advanced breast cancer and a germline BRCA mutation. $\mathrm{N}$ Engl J Med. 2018;379(8):753-63.
26. Aguirre E,Amillano K, Cortés A, Juan MJ, MárquezA, RuizM, et al. Abstract CT165: A two-stage Simon Design phase II study for Non-BRCA metastatic breast cancer (MBC) patients with homologous recombination deficiency treated with OLAparib single agent.(NOBROLA study). Cancer Res. 2018;78(13 Supplement):CT165.

27. Patsouris A, Tredan O, Nenciu D, Tran-Dien A, Campion L, Goncalves A, et al. RUBY: A phase II study testing rucaparib in germline (g) BRCA wild-type patients presenting metastatic breast cancer (mBC) with homologous recombination deficiency (HRD). J Clin Oncol. 2019;37(15_suppl):1092.

Publisher's Note Springer Nature remains neutral with regard to jurisdictional claims in published maps and institutional affiliations.

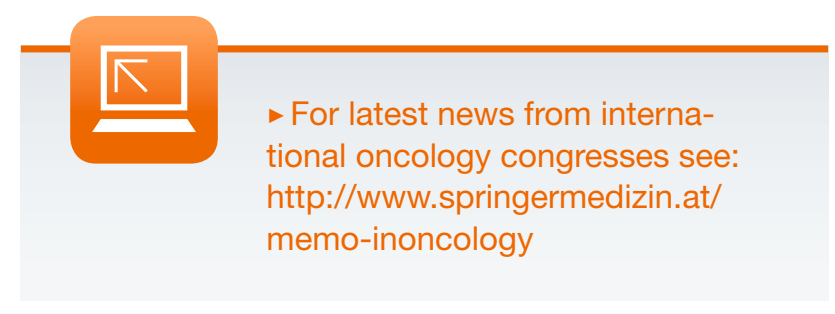

